\title{
Longitudinal Monitoring of Sex-Related in vivo Metabolic Changes in the Brain of Alzheimer's Disease Transgenic Mouse Using Magnetic Resonance Spectroscopy
}

\author{
Sara van Duijn ${ }^{\mathrm{a}, *}$, Rob J.A. Nabuurs ${ }^{\mathrm{b}}$, Sjoerd G. van Duinen ${ }^{\mathrm{a}}$, Remco Nattéa , \\ Mark A. van Buchem ${ }^{\mathrm{b}}$ and A. Alia ${ }^{\mathrm{b}, \mathrm{c}}$ \\ ${ }^{a}$ Department of Pathology, Leiden University Medical Center, Leiden, The Netherlands \\ ${ }^{\mathrm{b}}$ Department of Radiology, Leiden University Medical Center, Leiden, The Netherlands \\ ${ }^{\mathrm{c}}$ SSNMR, Leiden Institute of Chemistry, Gorlaeus Laboratoria, Leiden, The Netherlands
}

\begin{abstract}
Epidemiological studies indicate that the incidence of Alzheimer's disease (AD) is higher in women than in men. There is evidence that changes in metabolites in the brain associated with the development of AD are present earlier than structural brain changes. The effect of sex on the metabolic profile during the development of AD has not yet been studied. In this study we longitudinally monitored and compared in vivo metabolic changes in male and female A $\beta P$ swe, PSEN1dE9 transgenic mice brains using magnetic resonance spectroscopy. Our results show a lower level of glutamate as well as of N-acetylaspartate (NAA) in transgenic mice. The decline in NAA with age was more apparent in female mice. The level of taurine was higher in female mice and showed a faster decline over time. In conclusion, our study is the first to suggest that changes in the metabolic profile during $\mathrm{AD}$ development are influenced by sex.
\end{abstract}

Keywords: Alzheimer's disease, A $\beta P P / P S 1$ transgenic mouse model, longitudinal studies, magnetic resonance spectroscopy, sex differences

\section{INTRODUCTION}

Alzheimer's disease (AD) is a neurodegenerative disease that causes dementia and is an increasing health problem in the aging population; worldwide around 25 million people have $\mathrm{AD}$ and in 20 years this number will be doubled [1]. AD is associated with amyloid$\beta(A \beta)$ plaque formation, neurofibrillary tangles, and cerebral cortical atrophy, mainly found in the hippocampus and the cerebral cortex [2]. There are strong indications that the clinical symptoms of $\mathrm{AD}$ start

*Correspondence to: Sara van Duijn, Department of Pathology, Leiden University Medical Center, Albinusdreef 2, Leiden, The Netherlands. Tel.: +31 71 5266594; Fax: +31 71 5266952; E-mail: vanduijnsara@gmail.com. years after the onset of plaque formation [3]. Currently, $\mathrm{AD}$ can be diagnosed using a cognitive test combined with a magnetic resonance imaging (MRI) scan of the brain to detect cerebral atrophy and by determining the amount of $A \beta$ and tau in the cerebrospinal fluid, but not with complete accuracy [4]. Dementia and cerebral atrophy are very late stages of $\mathrm{AD}$; therefore, drugs that are able to modify the disease process can only be expected to have little effect. If patients could be diagnosed at the onset of neurodegeneration, when symptoms are absent or subtle, the therapeutic window for disease modifying drugs would be much wider and there would be an increased expected gain. Therefore, a more accurate and earlier diagnosis of $\mathrm{AD}$ is of vital importance. 
It is known that females are at higher risk for developing $\mathrm{AD}$ than men $[5,6]$. The effect of the mentioned sex differences on the pathophysiology of AD has not yet been carefully examined. Hormonal influences have been suggested [7], however, the underlying pathways accounting for the sex-related differences remain unknown. One way to examine the metabolic pathways non-invasively during early phases of $\mathrm{AD}$, and to study the influence of sex differences on these metabolic pathways, is by focusing on the metabolic changes in a transgenic ( $\mathrm{Tg}$ ) mouse model, by means of magnetic resonance spectroscopy (MRS). MRS is a noninvasive tool which can be used to measure the concentration of various brain metabolites in vivo [8]. Measuring these metabolic changes in vivo, using MRS, could help identify AD at an early stage, prior to the onset of cognitive symptoms [3]. Furthermore, changes in metabolic profiles could provide superior insight in the sex-related pathophysiologic mechanism of the disease.

Several Tg mouse models are available that develop pathology similar, however, not identical to human AD. These Tg mouse models allow monitoring of the metabolic changes from the onset of $\mathrm{AD}$, which is not detectable in patients. In the present study, the AßPPswe,PSEN1dE9 mouse model is used. This mouse model demonstrates many of the cognitive [9] and neuropathological features of human AD, including plaque development. These mice develop plaques at 6 months of age and show decreased performance of exploratory activity and spatial learning tests at 12 months of age [9]. In reproductive phenotype, no differences are found between this mouse model and control mice. Studies using this mouse model have mainly focused on histological data, including staining for $A \beta$, iron, and glial cells [10-16]. Among these histological studies, no sex-related differences were reported. However, in other AD mouse models, a sex-related difference was found, showing more $A \beta$ in female mice $[17$, 18]. For glial cells, no sex difference was found yet.

Numerous MRS studies have been performed using Tg mouse models of AD. However, until now, the effect of sex on AD-related metabolic changes has not been studied. The results of previous MRS studies have shown AD-related abnormalities for several metabolites [11, 16, 19-25]. N-acetylaspartate (NAA) in the brain is present predominantly in neuronal cell bodies. Decreased NAA levels, indicating neuronal damage, have been found in $\mathrm{Tg}$ mice in comparison to wild type (wt) mice [11, 20-24]. Myo inositol (mIns) and taurine play a role in osmoregulation and are mainly found in astrocytes of brain tissue. These metabolites were found to be higher in $\mathrm{Tg}$ mice than in wt mice [11, 19-22]. Glutamate (glu) is an excitatory neurotransmitter, involved in learning, memory formation, and cognition, which is found to be decreased in mice with AD [20-25]. Whether the changes in these metabolites during $\mathrm{AD}$ progression are sex specific, and whether they correlate temporally with timing of plaque deposition in male and female mice, remained to be investigated.

In this paper, we present the first systematic longitudinal MRS study to investigate the sex-related differences in metabolic changes during development of $\mathrm{AD}$ in the AßPPswe, PSEN1dE9 mouse model. The main findings of this study were the differences between male and female mice in NAA, taurine, and histological data. These results suggest that changes in the metabolic profile during $\mathrm{AD}$ development are clearly influenced by sex. Based on this, future MRS studies should consider specifying sex of the mice used and analyzing the data for both sexes separately.

\section{MATERIAL AND METHODS}

Mice

In this study, $20 \mathrm{~A} \beta P P / P S 1 \mathrm{Tg}$ mice (12 male, 8 female); B6C3-Tg (AßPPswe, PSEN1dE9) $85 \mathrm{Dbo} / \mathrm{Jtg} / 0$ from the Jackson Laboratory (Bar Harbor, ME, USA) and $20 \mathrm{wt}$ littermates (7 male, 13 female) were used. Ten $\mathrm{Tg}$ mice and wt mice were followed for 18 months and scanned every 3 months (time points: 3, 6, 9, 12, 15, and 18 months). For each time point, following MRI, two Tg and two wt mice of the remaining $10 \mathrm{Tg}$ and $10 \mathrm{wt}$ mice were sacrificed for histological analysis; at time point 18 months, the mice used for the longitudinal study were sacrificed. The Institutional Animal Care and Animal Use Committee approved all the experiments in accordance with the NIH guide for the care and use of Laboratory animals. The mice were kept in a $12 \mathrm{~h}$ light/dark circle.

\section{Magnetic resonance spectroscopy}

All measurements were conducted at $25^{\circ} \mathrm{C}$ on a vertical wide-bore 9.4T Bruker Avance 400WB spectrometer, with a $1000 \mathrm{mTm}-1$ actively shielded imaging gradient insert (Bruker BioSpin, Ettlingen, Germany). The RF coil used was a $25 \mathrm{~mm}$ volume RF coil, specifically, a birdcage transmit/receive coil (Bruker BioSpin, Ettlingen, Germany). The system 
was interfaced to a Linux pc running Topspin 2.0 and Paravision 5.0 imaging software (Bruker BioSpin).

Mice were anesthetized for in vivo MRS measurements using isoflurane (Forene, Abott, UK), inhalation anesthesia, in addition with air and oxygen $(1: 1)$ at 0.2 liter/min. The anesthetic gas was administered via a special facemask, which also served as a fixation device for the mouse head since it was coupled to a specially designed toothbar to hold the head in place (Bruker Biospin $\mathrm{GmbH}$, Germany). The respiration rate of the mouse inside the probe was constantly monitored using a pressure transducer placed on the abdomen. The transducer was connected to a BioTrig acquisition module, which was interfaced to a BioTrig command module and laptop running BioTrig BT1 monitoring software (Bruker Biospin GmbH, Germany).

Localized $\mathrm{T}_{2}$-weighted multislice RARE images were acquired to select a volume of interest [25]. The MRS voxels were localized in the cortex-hippocampus regions in the mouse brain $\left(1.8 \times 3.5 \times 3.5 \mathrm{~mm}^{3}\right.$; $22 \mu \mathrm{l}$ ) (Fig. 1). The localized homogeneity was optimized by adjustment of first- and second-order shim coil currents using the FASTMAP sequence [26]. The field homogeneity in a $22 \mu \mathrm{l}$ voxel typically resulted in water line-widths of 20-25 Hz.

The PRESS (Point Resolved Spectroscopy) sequence [27] was used for $1 \mathrm{D}$ localized $1 \mathrm{H} \mathrm{MR}$ spectroscopy. This sequence uses 3 hermite RF pulses $\left(90^{\circ}, 180^{\circ}\right.$, and $\left.180^{\circ}\right)$. The sequence details are described by Mandal et al. [28]. The repetition time and echo time were $1500 \mathrm{~ms}$ and $15 \mathrm{~ms}$, respectively. The PRESS sequence used 2048 complex points, with a spectral width of $10 \mathrm{ppm}$. The final 1D spectra were obtained with number of scans of 256 and scan times of approximately $15 \mathrm{~min}$. The 1D PRESS sequences were preceded by a VAPOR sequence [29] for global water suppression. The sequence consists of 7 variable power RF pulses with an optimized relaxation delay. The relaxation delays $\tau_{1}-\tau_{7}$ - between the consecutive pulses were $150,80,160,80,100$, 37.11 , and $57.36 \mathrm{~ms}$. Water suppression bandwidth was set at $350 \mathrm{~Hz}$. Outer volume suppression (OVS) was combined in an interleaved mode with a water suppression scheme. This improves the localization performance and reduces the demands for spoiler gradients. The OVS scheme used a total of 18 hyperbolic secant RF pulses, each with $90^{\circ}$ nominal flip angle and $1 \mathrm{~ms}$ pulse length. The OVS slice thickness was $4 \mathrm{~mm}$ with a $0 \mathrm{~mm}$ gap to the voxel.

The acquired in vivo $1 \mathrm{D}$ MR spectra were analyzed using LCModel [30]. This calculates the best fit of the experimental spectrum based on a linear combination of model spectra. The final analysis was performed in the frequency domain; however, raw data (FIDS) was used as standard data input. The following metabolites were included in the basis set for LCModel: alanine (Ala), aspartate (Asp), creatine (Cr), $\gamma$-aminobutyric acid (GABA), glucose (Glc), glutamate (Glu), glutamine (Gln), glycerophosphocholine (GPC), choline (cho), phosphocholine (PCho), myoinositol (Ins), lactate (Lac), N-acetylacetate (NAA), $\mathrm{N}$-acetylaspartylglutamate (NAAG), phosphocreatine (PCr), phosphoethanolamine (PE), scyllo-inositol (sIns), and taurine. Quantification was obtained using the $\mathrm{tCr}$ resonance as an internal standard, in our study no difference was found in creatine. The LCModel fitting was performed over the spectral range from 0.2 to $4.2 \mathrm{ppm}$. Signal to Noise ratio was above 5 and a $\% \mathrm{SD}$ of 20 or lower.

A
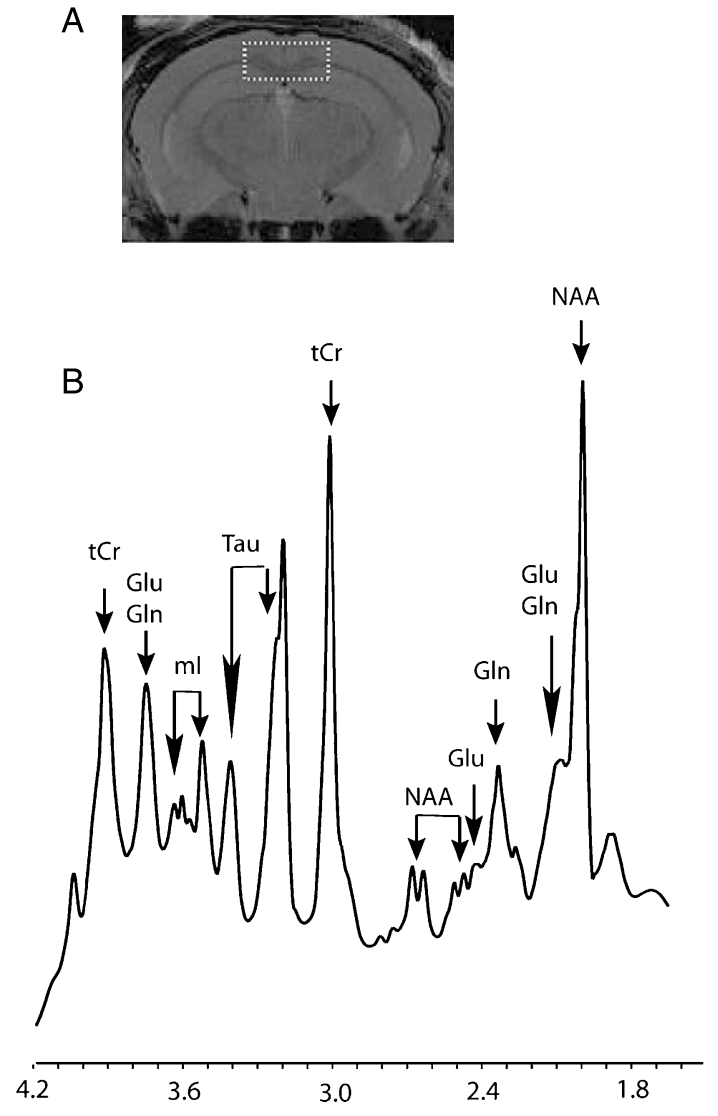

Fig. 1. Representative MR image and spectrum of the mouse brain. A) A coronal MR image of the mouse brain, obtained using RARE sequence, showing the position of the selected $22 \mu \mathrm{l}\left(1.8 \times 3.5 \times 3.5 \mathrm{~mm}^{3}\right)$ voxel covering the cortex-hippocampus region. B) One dimensional localized $1 \mathrm{H}-\mathrm{MR}$ spectrum obtained from the selected $22 \mu \mathrm{l}$ voxel placed in the brain of a 15-month old control mouse. Spectrum was obtained using a PRESS sequence with $\mathrm{TR}=1500 \mathrm{~ms}$ and $\mathrm{TE}=15 \mathrm{~ms}$ at $9.4 \mathrm{~T}$. 


\section{Histology}

Following in vivo MRS measurements, $2 \mathrm{wt}$ and $2 \mathrm{Tg}$ mice were sacrificed at each time point, and their brains were fixed in $4 \%$ buffered formaldehyde. Following fixation, the brain was dehydrated and embedded in paraffin, after which coronal sections ( $8 \mu \mathrm{m}$ thick) were carefully cut using a microtome. To detect the $\mathrm{A} \beta$ plaques, brain sections were pretreated for $1 \mathrm{~h}$ with $70 \%$ formic acid followed by treatment with trypsin for $30 \mathrm{~min}$ at $37^{\circ} \mathrm{C}$. Subsequently sections were washed in PBS and subjected to immunohistochemistry using the primary antibody polyclonal anti-amyloid 40-42 antibody at $1: 1000$ (Alpha Diagnostics International, San Antonio, USA) overnight followed by a secondary antibody swine anti-rabbit (Dako) $1: 600$ for $1 \mathrm{~h}$. After washing 3 times with PBS, immunolabeling was followed using a ABC kit (Vectastain) according to the manufacturer's instructions and visualized with DAB (3,3' diaminobenzidine, Sigma). Detection of iron was done by a DAB-enhanced Perl's staining according to Smith et al. [31]. To stain glial cells, a primary polyclonal anti-GFAP (glial fibrillary acidic protein) antibody (Dako) was used following standard procedure. To detect the activated microglia and macrophages, a primary polyclonal anti-IBA1 (ionized calcium binding adaptor molecule 1) antibody $1: 1000$ (Wako Chemicals, Neuss, Germany) was used. Prior to the IBA-1 antibody, a pretreatment with trypsin was performed for $30 \mathrm{~min}$ at $37^{\circ} \mathrm{C}$. Since the plaque development in AßPPswe, PSEN1dE9 Tg mouse starts at approximately 6 months of age, the histological data in male and female mice are shown at the age of 3,6 , and 9 months.

Histological images were acquired using a panoramic midi scanner (3D Histech, Budapest, Hungary). For quantitative histological analysis, regions of interest (ROIs) were selected in the cortex and hippocampus and the area percentage of stained tissue was calculated in these ROIs using ImageJ software (ImageJ, USA). The colors were unmixed using the plug-in color deconvolution, the stained area was selected, and the percentage of the total area was calculated using analyze particles.

\section{Statistical analysis}

To investigate significant age-related differences between either sex or Tg and controls, a mixed model analysis was performed including scatter plots using SPSS software (version 17.0; SPSS, Inc., Chicago, IL). Mean differences were compared using one way
ANOVA with statistical differences of $p<0.05$ stated as significant.

\section{RESULTS}

\section{Magnetic resonance spectroscopy}

Of all metabolites measured only glu, NAA, tau, and mIns are presented because they show either statistical significant results or a trend.

As shown in Fig. 2A, the glutamate (glu)/Cr ratio was lower in $\mathrm{Tg}$ mice compared to wt mice at all ages (Fig. 2A; Tables 1 and 2), and the rate of decline in $\mathrm{glu} / \mathrm{Cr}$ ratio with age was more pronounced in $\mathrm{Tg}$ mice than in wt mice. A sex difference in the level and rate of decline in glutamate became apparent after separation of the data of male and female mice. In male wt mice, the $\mathrm{glu} / \mathrm{Cr}$ ratio decreased over time, in contrast to wt female mice, in which it slightly increased. However, in $\mathrm{Tg}$ mice, the glu/Cr ratio decreased in both male and female. At 18 months, a significant difference $(p<0.05)$ is found between wt male $(0.84)$ and wt female $(0.97)$ mice, and between $\mathrm{Tg}$ male $(0.87)$ and $\mathrm{Tg}$ female (0.94) mice (Tables 1 and 2).

The NAA/Cr ratio was higher in wt mice in comparison to Tg mice (Fig. 2B; Tables 1 and 2) and decreased over time in both wt and in Tg mice. Overall the NAA/Cr ratio was higher in female when compared to male in both wt and $\mathrm{Tg}$ mice. In female mice a faster decrease in NAA/Cr ratio was observed in $\mathrm{Tg}$ than in wt mice leading to a more apparent difference at 18 months of age than in males. Female $\mathrm{Tg}$ mice showed a faster decline than male Tg mice (Fig. 2B (b,c)).

When male and female mice were taken together, the ratio of taurine/Cr was similar for $\mathrm{Tg}$ and wt mice at all time points (Fig. 2D; Tables 1 and 2). Male wt and $\mathrm{Tg}$ mice showed a comparable taurine/Cr ratio at 3 months and a similar decrease over time. Female $\mathrm{Tg}$ mice showed a much stronger decline compared with male $\mathrm{Tg}$ and female wt mice. The taurine/Cr ratio in female Tg mice started higher at 3 months and ended lower at 18 months than in male $\mathrm{Tg}$, female wt, and male wt mice.

In $\mathrm{Tg}$ mice, the mIns/Cr ratio started lower than in the wt mice and increased over time while this ratio slightly decreased in wt mice (Fig. 2C; Tables 1 and 2). Separating male and female mice showed comparable results.

\section{Histology}

Figure 4 shows the results of $A \beta$ in the brain sections of 6 and 9 month old male $\mathrm{Tg}$ and female Tg mice. The 


$$
\sigma^{7}+q
$$

A

B
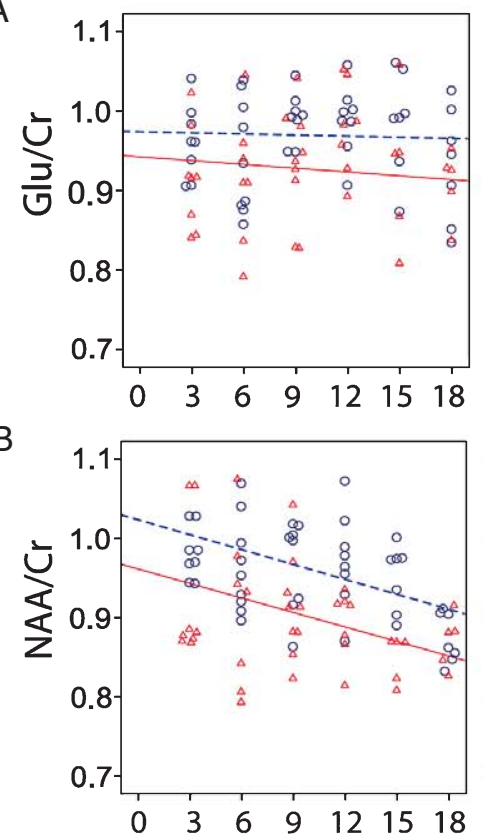

C

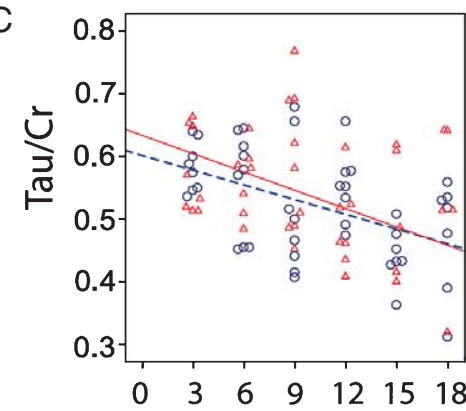

D

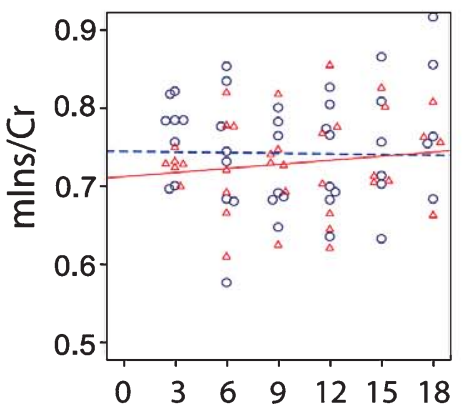

ه7
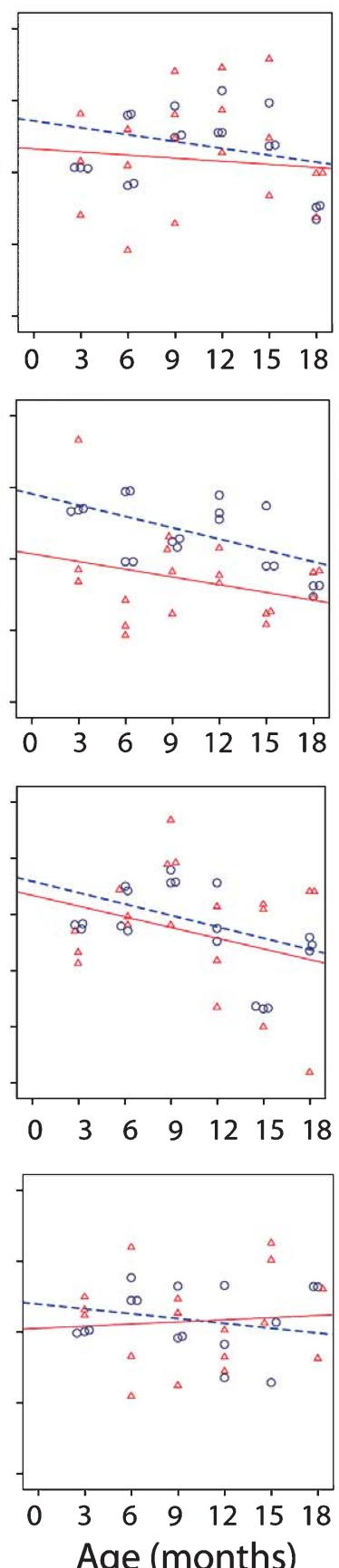

q
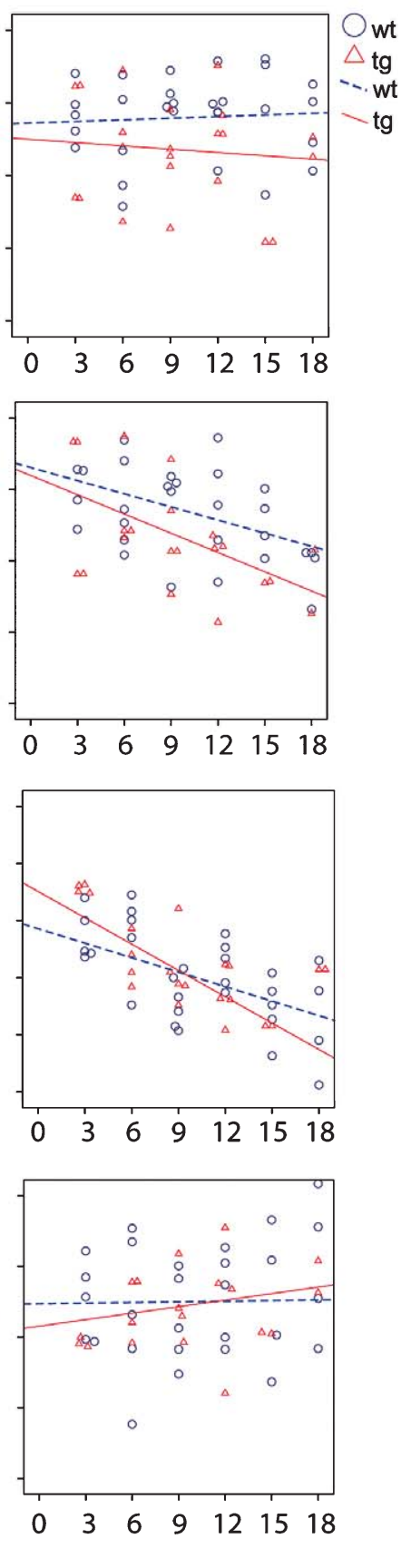

Fig. 2. Longitudinal monitoring of sex-related differences in (A) glutamate (glu)/creatine (Cr) ratio, (B) N-acetylaspartate (NAA)/Cr ratio, (C) $\mathrm{Tau} / \mathrm{Cr}$ ratio, and (D) Myo inositol (mIns)/Cr ratio in the cortex-hippocampus regions of all mice, male and female mouse brain measured using in vivo MRS at $9.4 \mathrm{~T}$. 
Table 1

$\mathrm{R}^{2}$ of the linear regression line of the metabolic changes over time in wild type (WT) and transgenic (TG) mice. The differences are shown in male $(\mathrm{M})$ and female $(\mathrm{F})$ for glutamate, $\mathrm{N}$-acetylaspartate (NAA), taurine, and myo inositol

\begin{tabular}{lcccc}
\hline$R^{2}$ & Glutamate & NAA & Taurine & Myo inositol \\
\hline WT & 0.00 & 0.21 & 0.20 & 0.00 \\
TG & 0.01 & 0.14 & 0.19 & 0.02 \\
M WT & 0.07 & 0.26 & 0.22 & 0.04 \\
M TG & 0.01 & 0.08 & 0.08 & 0.01 \\
F WT & 0.01 & 0.18 & 0.29 & 0.00 \\
F TG & 0.01 & 0.29 & 0.54 & 0.05 \\
\hline
\end{tabular}

$\mathrm{A} \beta$ deposition in the brain increased more rapidly in $\mathrm{Tg}$ female mice than in Tg male mice (Fig. 4A). Iron deposition showed the same pattern as $A \beta$ deposition. No $A \beta$ or iron deposition was found in wt mice, even at 9 months.
This difference between male and female was more prominent in the cortex than in the hippocampus (Figs. 3 and 4).

Quantification of the amount of GFAP and IBA-1 showed no difference between wt and Tg mice. However, in the $\mathrm{Tg}$ mouse brain the distribution of both GFAP and IBA-1 became irregular over time, because GFAP and IBA-1 positive cells aggregate around plaques (Fig. 4B, C). In wt mice, the deposition of GFAP and IBA-1 was more evenly distributed than in Tg mice (Fig. 4B, C). The presence of these plaque associated GFAP depositions was visible earlier in female brain than in male brain (Fig. 4B).

\section{DISCUSSION}

This is the first longitudinal study showing that changes in metabolic profile during $\mathrm{AD}$ development

Table 2

Mean ratio of glutamate, $\mathrm{N}$-acetylaspartate (NAA), taurine, and Myo inositol with respect to creatine in 3 and 18 months old wild type (wt) and transgenic $(\mathrm{Tg})$ mice (mean \pm standard deviation). Wt and Tg were separated in male $(\mathrm{M})$ and female $(\mathrm{F})$

\begin{tabular}{|c|c|c|c|c|c|c|c|c|}
\hline & \multicolumn{2}{|c|}{ Glutamate } & \multicolumn{2}{|c|}{ NAA } & \multicolumn{2}{|c|}{ Taurine } & \multicolumn{2}{|c|}{ Myo inositol } \\
\hline & 3 months & 18 months & 3 months & 18 months & 3 months & 18 months & 3 months & 18 months \\
\hline WT & $0.97 \pm 0.05$ & $0.93 \pm 0.07$ & $1.01 \pm 0.08$ & $0.87 \pm 0.35$ & $0.58 \pm 0.04$ & $0.47 \pm 0.09$ & $0.79 \pm 0.11$ & $0.79 \pm 0.83$ \\
\hline TG & $0.93 \pm 0.08$ & $0.90 \pm 0.05$ & $0.95 \pm 0.01$ & $0.87 \pm 0.04$ & $0.59 \pm 0.07$ & $0.44 \pm 0.17$ & $0.73 \pm 0.02$ & $0.75 \pm 0.06$ \\
\hline M wt & 0.91 & $0.84 \pm 0.01 *$ & 0.97 & $0.86 \pm 0.01$ & 0.57 & $0.55 \pm 0.02$ & 0.70 & 0.76 \\
\hline M Tg & $0.91 \pm 0.07$ & $0.87 \pm 0.04 *$ & $0.94 \pm 0.11$ & $0.86 \pm 0.03$ & $0.54 \pm 0.03$ & $0.48 \pm 0.23$ & $0.74 \pm 0.01$ & $0.71 \pm 0.07$ \\
\hline F wt & $0.98 \pm 0.04$ & $0.97 \pm 0.05 *$ & $1.03 \pm 0.09$ & $0.88 \pm 0.04$ & $0.58 \pm 0.05$ & $0.45 \pm 0.09$ & $0.81 \pm 0.11$ & $0.80 \pm 0.09$ \\
\hline $\mathrm{F} \mathrm{Tg}$ & $0.95 \pm 0.11$ & $0.94 \pm 0.02 *$ & $0.97 \pm 0.13$ & $0.87 \pm 0.06$ & $0.66 \pm 0.01$ & $0.39 \pm 0.17$ & 0.70 & $0.79 \pm 0.03$ \\
\hline
\end{tabular}

*Difference between male and female mice at 18 months for glutamate was significant $(p<0.05)$ for both wt and Tg

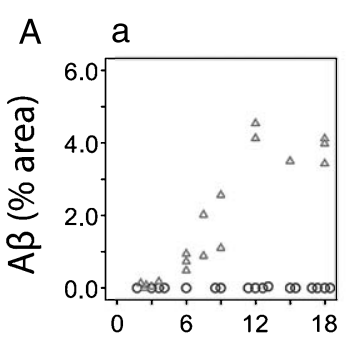

B

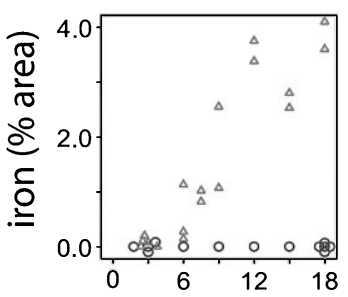

b
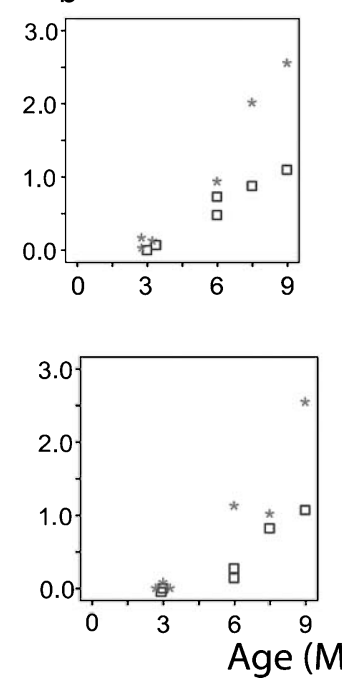

C
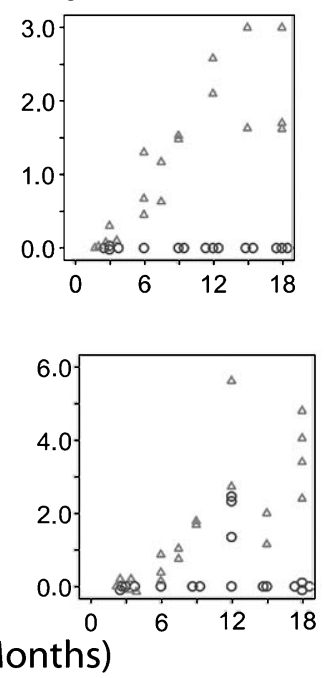

d
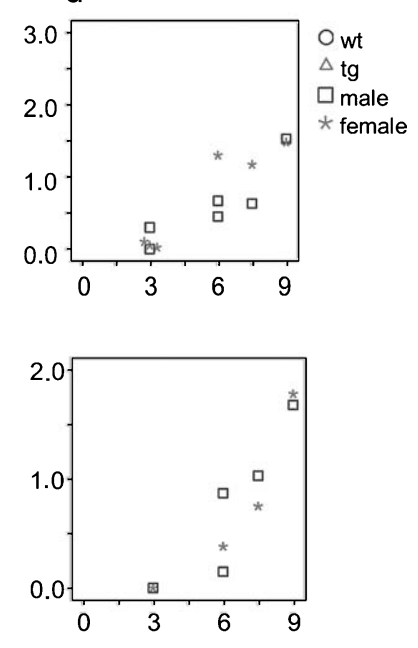

Fig. 3. Quantitative analysis of sex-related differences in $\mathrm{A} \beta$ (A) and iron (B) deposition in wt and tg mouse brain. a) Surface percentage (\%) of deposition in the cortex of wt and Tg mice; (b) \% of deposition in the cortex of male and female Tg mice; (c) \% of deposition in the hippocampus of wt and Tg mice; (d) \% of deposition in the hippocampus of male and female Tg mice. Percentage of A $\beta$ and iron deposition in the cortex and hippocampus elevate during the development of $\mathrm{AD}$ in $\mathrm{Tg}$ mice. The elevation starts earlier in female mice as compared to male mice. 


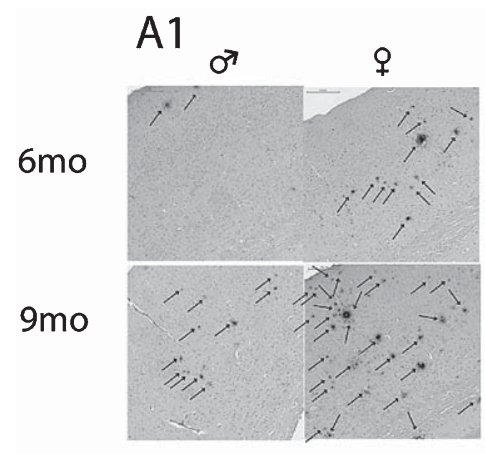

\section{C1}

$6 \mathrm{mo}$

$9 \mathrm{mo}$

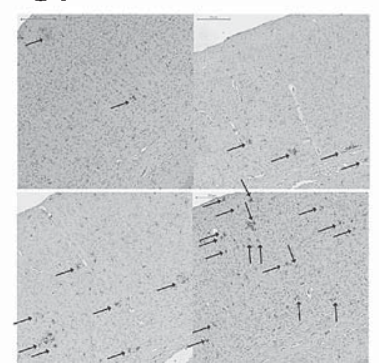

A2

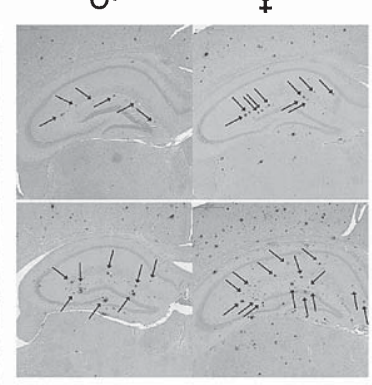

$\mathrm{C2}$

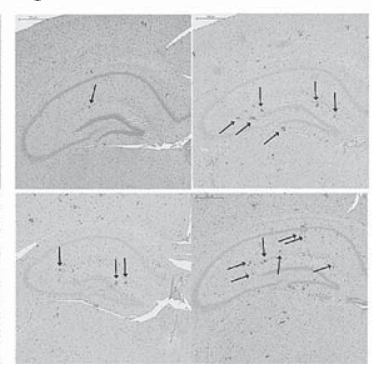

B1 $\quad \circ \quad$ B2
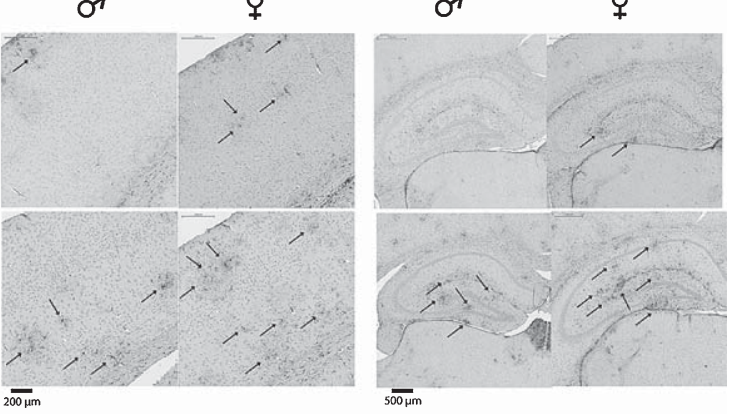

Fig. 4. A $\beta$ staining (A), GFAP staining (B), and IBA-1 staining (C) in brain sections of 6 month (6 mo) and 9 month (9 mo) old transgenic male and female mice. Magnified area of (1) cortex (scale bar, $200 \mu \mathrm{m}$ ) and (2) hippocampus (scale bar, $500 \mu \mathrm{m}$ ) is shown. Arrows indicate immune stained A $\beta$ plaques, GFAP depositions, and IBA-1 depositions.

are influenced by sex in a mouse model of AD. The main findings of this study are: 1) female mice have increased plaque development as well as increased activation of microglia surrounding the plaques compared with male mice; and 2) the decline in NAA and taurine during $\mathrm{AD}$ development is more apparent in female $\mathrm{Tg}$ mice than in male $\mathrm{Tg}$ mice in both the cortex and hippocampus. Most of these differences are statistically not significant, probably due to the low number of mice and lower inter individual variability at the different time points, but a trend is apparent. We tried to limit inter individual variability by scanning the wt and Tg mice for each time point at the same day with the same protocol. Instrumental limitations were excluded as far as possible by doing phantom studies, being preparations with known amounts of metabolites.

One lesson we learned from our study is that sexspecific differences between animals can influence study results. Comparison of wt and $\mathrm{Tg}$ mice show different results than comparison of the individual male and female subpopulation. For instance, the difference in NAA/Cr ratio between female wt and $\mathrm{Tg}$ mice increases over time, while for male $\mathrm{Tg}$ and wt mice, the difference in NAA/Cr ratio decreases. This may explain why the results, as presented in our study, differ at some parameters from earlier studies [11, 22, 23, 25].

We observed an increase of the glu/Cr ratio in female wt mice and a decrease in male wt mice over time, which indicates that the glu/Cr ratio between wt and $\mathrm{Tg}$ is sex dependent. In several earlier studies glu/Cr ratio changes were observed, but the sex of the studied mice was not mentioned or sex was not taken into account in the analysis of the data $[11,21,22,24]$.

In a previous study [22], mIns was increased in Tg mice compared with wt mice, however male and female mice in the Tg group were presented together, while only female wt mice were used, which means the two groups could in fact not be compared due to the sex differences. Chen et al. [11] found no significant differences between male and female and this study confirmed the differences between $\mathrm{Tg}$ and wt mice found by Marjanska et al. [22].

The ratio of taurine/Cr was higher in female $\mathrm{Tg}$ mice than in wt mice at an early age ( 3 and 6 month) but at 9 months the taurine/Cr ratio was lower in female $\mathrm{Tg}$ mice. However, the mIns/Cr ratio started slightly lower in the Tg mice than in the wt mice (3 and 6 months), but, at 12 month the ratio of mIns/Cr was higher in the $\mathrm{Tg}$ mice than in the wt mice. Myo inositol and taurine are known to be involved in osmotic regulation 
across the cellular membrane and are mostly present in glial cells [22]. Despite these functional similarities, our results indicate that in $\mathrm{Tg}$ mice the two metabolites show an opposite trend; mIns slightly increases with age (as opposed to a stable amount in wt) and taurine decreases with age (more than the decrease in wt).

Our histological data show an increase in plaque deposition in Tg mice which was correlated with an increase in iron as well as an increase of GFAP positive glial cells around plaques with age. This increase was more apparent in the female mice. Previous histological studies in A $\beta P P / P S 1$ mice have shown an increase in plaque deposition after 3 to 5 months. In addition, an increase in GFAP positive glial cells is reported in these mice at 5-8 months $[11,14,15,32]$. However, these studies did not show sex differences in deposition of plaque, iron, or GFAP.

Although the pattern of GFAP positive cells changes while plaques develop in the brain, the overall density of these cells is not clearly different between wt and $\mathrm{Tg}$ brain tissue. This is reflected by the minimal increase of myo inositol and even a decrease of taurine, both osmoregulatory proteins, which are particularly present in glial cells.

The increased level of the NAA/Cr ratio in the female brain, for both wt and Tg mice, can be explained by the fact that females seem to have a higher cerebral axonal density than males [33]. The mechanisms responsible for the sex differences in $A \beta$ and iron deposition are not yet known.

Our study is the first study to systematically investigate the influence of sex on metabolic and histological changes in $\mathrm{AD}$ over time using an $\mathrm{AD}$ mouse model. The use of a mouse model allows examining early changes in $\mathrm{AD}$, which is not possible in humans. Our findings show for the first time that changes in metabolic profile during AD development is influenced by sex. These results are in line with the known higher risk of $\mathrm{AD}$ in women $[5,6]$. The area of sex differences in AD is still largely unexplored but knowledge of metabolic differences would offer great promise for diagnosis and for the future development of better strategies for intervention in patients.

\section{ACKNOWLEDGMENTS}

We thank Ingrid Hegeman for her excellent assistance and H.E. Kan, A.G. Webb and I. Ronen for useful suggestions and discussions. This work was supported by grants from Department of Pathology (LUMC). Alia thanks grant support from Internationale Stichting
Alzheimer Onderzoek (ISAO) and Centre for Medical Systems Biology (CMSB).

Authors' disclosures available online (http://www.jalz.com/disclosures/view.php?id=1623).

\section{REFERENCES}

[1] Ferri CP, Prince M, Brayne C, Brodaty H, Fratiglioni L, Ganguli M, Hall K, Hasegawa K, Hendrie H, Huang Y, Jorm A, Mathers C, Menezes PR, Rimmer E, Scazufca M (2005) Global prevalence of dementia: A Delphi consensus study. Lancet 366, 2112-2117.

[2] Price JL, Davis PB, Morris JC, White DL (1991) The distribution of tangles, plaques and related immunohistochemical markers in healthy aging and Alzheimer's disease. Neurobiol Aging 12, 295-312.

[3] Jack CR Jr, Knopman DS, Jagust WJ, Shaw LM, Aisen PS, Weiner MW, Petersen RC, Trojanowski JQ (2010) Hypothetical model of dynamic biomarkers of the Alzheimer's pathological cascade. Lancet Neurol 9, 119-128.

[4] Fox NC, Freeborough PA, Rossor MN (1996) Visualisation and quantification of rates of atrophy in Alzheimer's disease. Lancet 348, 94-97.

[5] Musicco M (2009) Gender differences in the occurrence of Alzheimer's disease. Funct Neurol 24, 89-92.

[6] Andersen K, Launer LJ, Dewey ME, Letenneur L, Ott A, Copeland JR, Dartigues JF, Kragh-Sorensen P, Baldereschi M, Brayne C, Lobo A, Martinez-Lage JM, Stijnen T, Hofman A (1999) Gender differences in the incidence of AD and vascular dementia: The EURODEM Studies. EURODEM Incidence Research Group. Neurology 53, 1992-1997.

[7] Janicki SC, Schupf N (2010) Hormonal influences on cognition and risk for Alzheimer's disease. Curr Neurol Neurosci Rep 10, 359-366.

[8] Rupsingh R, Borrie M, Smith M, Wells JL, Bartha R (2011) Reduced hippocampal glutamate in Alzheimer disease. Neurobiol Aging 32, 802-810.

[9] Lalonde R, Kim HD, Maxwell JA, Fukuchi K (2005) Exploratory activity and spatial learning in 12-monthold APP(695)SWE/co + PS1/DeltaE9 mice with amyloid plaques. Neurosci Lett 390, 87-92.

[10] Bereczki E, Bernat G, Csont T, Ferdinandy P, Scheich H, Santha M (2008) Overexpression of human apolipoprotein B-100 induces severe neurodegeneration in transgenic mice. J Proteome Res 7, 2246-2252.

[11] Chen SQ, Wang PJ, Ten GJ, Zhan W, Li MH, Zang FC (2009) Role of myo-inositol by magnetic resonance spectroscopy in early diagnosis of Alzheimer's disease in APP/PS1 transgenic mice. Dement Geriatr Cogn Disord 28, 558-566.

[12] Connor DM, Benveniste H, Dilmanian FA, Kritzer MF, Miller LM, Zhong Z (2009) Computed tomography of amyloid plaques in a mouse model of Alzheimer's disease using diffraction enhanced imaging. Neuroimage 46, 908-914.

[13] Hooijmans CR, Rutters F, Dederen PJ, Gambarota G, Veltien A, van GT, Broersen LM, Lutjohann D, Heerschap A, Tanila H, Kiliaan AJ (2007) Changes in cerebral blood volume and amyloid pathology in aged Alzheimer APP/PS1 mice on a docosahexaenoic acid (DHA) diet or cholesterol enriched Typical Western Diet (TWD). Neurobiol Dis 28, 16-29.

[14] Manaye KF, Wang PC, O’Neil JN, Huang SY, Xu T, Lei DL, Tizabi Y, Ottinger MA, Ingram DK, Mouton PR (2007) Neuropathological quantification of dtg APP/PS1: Neuroimaging, stereology, and biochemistry. Age 29, 87-96. 
[15] Ruan L, Kang Z, Pei G, Le Y (2009) Amyloid deposition and inflammation in APPswe/PS1dE9 mouse model of Alzheimer's disease. Curr Alzheimer Res 6, 531-540.

[16] Xu W, Zhan YQ, Huang W, Wang XX, Zhang SM, Lei H (2010) Reduction of hippocampal N-acetyl aspartate level in aged APP(Swe)/PS1(dE9) transgenic mice is associated with degeneration of CA3 pyramidal neurons. J Neurosci Res $\mathbf{8 8}$, 3155-3160.

[17] Wang J, Tanila H, Puolivali J, Kadish I, van GT (2003) Gender differences in the amount and deposition of amyloidbeta in APPswe and PS1 double transgenic mice. Neurobiol Dis 14, 318-327.

[18] Callahan MJ, Lipinski WJ, Bian F, Durham RA, Pack A, Walker LC (2001) Augmented senile plaque load in aged female beta-amyloid precursor protein-transgenic mice. Am J Pathol 158, 1173-1177.

[19] Westman E, Spenger C, Oberg J, Reyer H, Pahnke J, Wahlund LO (2009) In vivo $1 \mathrm{H}$-magnetic resonance spectroscopy can detect metabolic changes in APP/PS1 mice after donepezil treatment. BMC Neurosci 10, 33.

[20] Choi JK, Jenkins BG, Carreras I, Kaymakcalan S, Cormier K, Kowall NW, Dedeoglu A (2010) Anti-inflammatory treatment in $\mathrm{AD}$ mice protects against neuronal pathology. Exp Neurol 223, 377-384.

[21] Dedeoglu A, Choi JK, Cormier K, Kowall NW, Jenkins BG (2004) Magnetic resonance spectroscopic analysis of Alzheimer's disease mouse brain that express mutant human APP shows altered neurochemical profile. Brain Res 1012, 60-65.

[22] Marjanska M, Curran GL, Wengenack TM, Henry PG, Bliss RL, Poduslo JF, Jack CR Jr, Ugurbil K, Garwood M (2005) Monitoring disease progression in transgenic mouse models of Alzheimer's disease with proton magnetic resonance spectroscopy. Proc Natl Acad Sci U S A 102, 11906-11910.

[23] Oberg J, Spenger C, Wang FH, Andersson A, Westman E, Skoglund P, Sunnemark D, Norinder U, Klason T,
Wahlund LO, Lindberg M (2008) Age related changes in brain metabolites observed by 1H MRS in APP/PS1 mice. Neurobiol Aging 29, 1423-1433.

[24] von Kienlin M, Kunnecke B, Metzger F, Steiner G, Richards JG, Ozmen L, Jacobsen H, Loetscher H (2005) Altered metabolic profile in the frontal cortex of PS2APP transgenic mice, monitored throughout their life span. Neurobiol Dis $\mathbf{1 8}$, 32-39.

[25] Braakman N, Oerther T, de Groot HJ, Alia A (2008) High resolution localized two-dimensional MR spectroscopy in mouse brain in vivo. Magn Reson Med 60, 449-456.

[26] Gruetter R (1993) Automatic, localized in vivo adjustment of all first- and second-order shim coils. Magn Reson Med 29, 804-811.

[27] Bottomley PA (1987) Spatial localization in NMR spectroscopy in vivo. Ann N Y Acad Sci 508, 333-348.

[28] Mandal PK (2007) Magnetic resonance spectroscopy (MRS) and its application in Alzheimer's disease. Conc Magn Reson A 30A, 40-64.

[29] Tkac I, Starcuk Z, Choi IY, Gruetter R (1999) In vivo $1 \mathrm{H} \mathrm{NMR}$ spectroscopy of rat brain at $1 \mathrm{~ms}$ echo time. Magn Reson Med 41, 649-656.

[30] Provencher SW (1993) Estimation of metabolite concentrations from localized in vivo proton NMR spectra. Magn Reson Med 30, 672-679.

[31] Smith MA, Harris PL, Sayre LM, Perry G (1997) Iron accumulation in Alzheimer disease is a source of redox-generated free radicals. Proc Natl Acad Sci U S A 94, 9866-9868.

[32] Taniuchi N, Niidome T, Goto Y, Akaike A, Kihara T, Sugimoto H (2007) Decreased proliferation of hippocampal progenitor cells in APPswe/PS1dE9 transgenic mice. $\mathrm{Neu}$ roreport 18, 1801-1805.

[33] Wilkinson ID, Paley MN, Miszkiel KA, Hall-Craggs MA, Kendall BE, Chinn RJ, Harrison MJ (1997) Cerebral volumes and spectroscopic proton metabolites on MR: Is sex important? Magn Reson Imaging 15, 243-248. 